\title{
Cat scratch disease in Greece
}

\author{
T Karpathios, C Golphinos, P Psychou, A Garoufi, A Papadimitriou, P Nicolaidou
}

\begin{abstract}
An indirect fluorescent antibody test for Bartonella henselae, $B$ quintana, and $B$ elizabethae was performed in all 18 children who presented to our paediatric outpatient clinic with cat scratch disease over a six year period. Serum samples were taken on admission, after 15 days, and after six months. Diagnosis was confirmed in 15 patients $(83 \%)$ and was based on seroconversion or a fourfold change of the antibody titre to $B$ henselae in 12 patients and on a single high titre $(>128)$ in three patients. Lymphadenopathy was present in all patients, erythema nodosum in one, osteomyelitis in one, hepatitis in one, transverse myelitis in one, and liver or spleen granulomata, or both, in three patients. Cat scratch disease developed in autumn or winter in 12 patients. All had a history of physical contact with a cat. Our study shows that our clinical suspicion was accurate in the diagnosis of cat scratch disease in a high percentage of patients presenting to a hospital and that indirect fluorescent antibody testing for $B$ henselae is a useful diagnostic tool. (Arch Dis Child 1998;78:64-66)
\end{abstract}

Keywords: cat scratch disease; lymphadenopathy; Bartonella henselae

Cat scratch disease is a relatively common benign infectious disease which has been shown to be caused by Bartonella henselae. ${ }^{12}$ Cat scratch disease affects people of all ages, although more than $80 \%$ of patients are less than 21 years of age. ${ }^{3}$ The disease typically manifests itself with regional lymphadenitis, which follows the development of a papule that occurs one to two weeks after a scratch or bite from an infected cat. The lymphadenopathy is proximal to the inoculation site and usually resolves in two to four months. ${ }^{3}$ About $5-14 \%$ of patients may, however, present with symptoms other than regional lymphadenopathyfor example, Parinaud's oculoglandular syndrome, encephalopathy, neuroretinitis, and severe systemic disease. ${ }^{4}$

Before the advent of an indirect fluorescent antibody test which detects a humoral response to $B$ henselae or the detection of the $B$ henselae antigen in infected tissue by polymerase chain reaction, the diagnosis of cat scratch disease was mainly clinical using the criteria of Carithers $^{34}$ or Carithers and Margileth. ${ }^{5}$

We present here our experience with cat scratch disease serologically proved in a paediatric population in Greece whose antibody titres were followed up for six months.
Subjects and methods

This prospective study was conducted between January 1990 and December 1995. During the study period all children who presented to the outpatient clinic of our department and were diagnosed clinically with cat scratch disease were included in the study. A clinical case of cat scratch disease was defined as the occurrence of regional lymphadenopathy in a patient with a history of cat contact and negative studies for other causes of lymphadenopathy.

During the six years of the study 18 patients were diagnosed clinically with cat scratch disease. Serum samples were obtained whenever possible on the day of admission (18 samples), after 15 days ( 15 samples), and after six months (12 samples). Serum samples were frozen at $-70^{\circ} \mathrm{C}$ and then sent to the Centers for Disease Control and Prevention in Atlanta, Georgia, USA, where they were serologically tested by indirect immunofluorescence for the presence of antibodies to $B$ henselae, $B$ quintana, and $B$ elizabethae. ${ }^{6}$ An indirect fluorescent antibody titre of equal to or $>64$ was considered as indicative of infection with $B$ henselae. If an acute phase titre did not indicate infection, the demonstration of a fourfold increase in the serum sample taken during the convalescent phase was also considered diagnostic of infection.

Routine laboratory studies included a full blood count, erythrocyte sedimentation rate, C reactive protein, liver and renal function tests, and ultrasonographic examination of the liver and spleen. When appropriate a ${ }^{99 \mathrm{~m}} \mathrm{Tc}-\mathrm{MDP}$ bone scan, ophthalmological examination, and central nervous system studies were carried out. A dermal biopsy sample was taken from seven children, and a lymph node biopsy sample from four.

A standardised questionnaire was used to collect data on the type and exact time of contact with the implicated cat, as well as the age of the animal. Informed consent was obtained from the parents of all children participating in the study.

\section{Results}

Diagnosis of cat scratch disease was confirmed in 15 of 18 patients ( $83 \%$ ) and was based on seroconversion or a fourfold change in the antibody titre to $B$ henselae in 12 patients and on a single high titre $(>128)$ in three patients. Three children had a low antibody titre $(<32)$ to $B$ henselae, $B$ quintana, and $B$ elizabethae on admission, which did not change during the six months of the study. These children were not considered to have cat scratch disease. Figure 1 shows antibody titres to $B$ henselae and $B$ quintana in serum samples from the 15 patients. Serum samples positive to $B$ henselae were also 

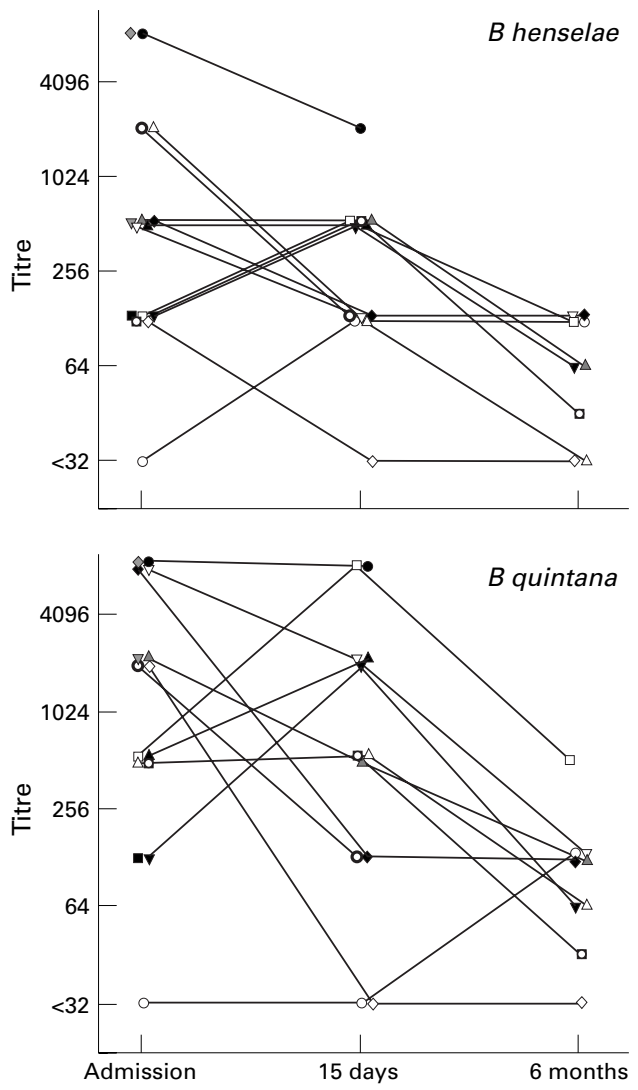

Figure 1 B henselae and B quintana antibody titres in 15 children with cat scratch disease.

positive to $B$ quintana. Titres to $B$ quintana were usually higher than those to $B$ henselae. Only one child, with increased $B$ henselae and $B$ quintana titres, also had positive titres to $B$ elizabethae at 15 days and six months.

There were 12 boys and three girls. The median age was 10 years (range 5.5-13.5). The median duration of symptoms before admission was 10 days (range 8-55 days).

All children had a history of scratches and seven reported that they were licked and two were also bitten by a cat. Thirteen patients owned the implicated cat, which was younger than 1 year in 12 cases. The interval between the animal contact and the onset of lymphadenopathy or other constitutional symptoms ranged from 15 to 60 days (median 30 days). Lymphadenopathy was present in all patients, the axilla being the most common site. Physical examination disclosed a dermal lesion suggestive of cat scratch disease in 11 children; 10 children had scratches and three granulomata. Other unusual manifestations of cat scratch disease were erythema nodosum in one, osteomyelitis in one, hepatitis in one, transverse myelitis in one, and liver or spleen granulomata, or both, in three patients. Fever $>38^{\circ} \mathrm{C}$ was present in three children.

The three children not serologically proved to have cat scratch disease had a history of contact with a cat and lymphadenopathy. None of these children presented with dermal lesions or the other clinical manifestations such as those found in the patients with proved cat scratch disease.
Seven patients developed cat scratch disease in autumn, five in winter, and three during the summer. All children had normal total and differential white blood cell counts; five had an increased erythrocyte sedimentation rate $(>40$ $\mathrm{mm} /$ hour); three had increased $\mathrm{C}$ reactive protein $(>30 \mathrm{mg} / \mathrm{l})$; and one had increased levels of liver enzymes. All four lymph node biopsy samples, but only two of the seven dermal biopsy samples, showed histopathological changes consistent with cat scratch disease.

Antibiotics - usually third generation cephalosporin, aminoglycoside, trimethoprim-sulphamethoxazole, or chloramphenicol-were prescribed for 14 patients. All patients recovered without sequelae.

\section{Discussion}

Our study shows that clinical suspicion, based on the presence of regional lymphadenopathy and a history of contact with a cat, was accurate in the diagnosis of cat scratch disease in a high percentage $(83 \%)$ of patients. Serology for antibodies to $B$ henselae made the diagnosis easy and rapid, preventing these patients from unnecessary investigations or surgery. The indirect fluorescent antibody test is reported to be highly sensitive (88\%) and specific (94\%) for the diagnosis of cat scratch disease. ${ }^{6}$

In the second serum sample, taken 15 days after admission, antibody titres remained stable or showed a fourfold increase or decrease. This may be due to the wide range of incubation time, reported to be from seven to 60 days, or to the variable duration of the disease before admission and probably also to the administration of antibiotics. ${ }^{7}$ Although cell mediated immunity is of major importance in the pathogenesis of cat scratch disease, ${ }^{8}$ the short duration of the antibody response in three of our patients who lost detectable antibodies after six months raises the possibility that reinoculation and recurrent infection might be possible, even in immunocompetent children. Recurrent cat scratch disease has been reported in adults. ${ }^{9}$

All of our patients also had high titres of antibodies to $B$ quintana. This is presumably due to cross reactivity ${ }^{10}$ as $B$ quintana is not thought to cause cat scratch disease. ${ }^{11}$

The fact that most of our patients were boys is in agreement with other studies. ${ }^{3}$ This may be due to the more aggressive behaviour of boys, which leads to an increased possibility of them being bitten or scratched by cats. All of our patients, except one, were older than 7 years. This is in contrast with other studies reporting a substantial number of younger patients. It may be that, in Greece, families with small children avoid having a housebound cat or that cat scratch disease is underdiagnosed in this age group.

We found a seasonal distribution similar to that reported previously. ${ }^{12}$ In 12 of our patients cat scratch disease developed in autumn or winter. This may be related to the biological cycle of cat fleas, which may have a role in the transmission of $B$ henselae to kittens. Cats usually become pregnant in spring or early autumn, gestation lasting about nine weeks and 
weaning six to nine weeks. Therefore kittens become available for contact with children and possible transmission of cat scratch disease from late summer to midwinter. Flea breeding also peaks in late summer.

It is reported that most patients with cat scratch disease are managed as outpatients. ${ }^{4}$ Although our study was prospective, we only see the more severely affected children presenting to our hospital and so cannot describe the full clinical spectrum of cat scratch disease. This probably accounts for the high rate of complications seen in our study group. The incubation period of the disease was similar to that reported by others. The estimation is uncertain, however, because in most instances the cat was housebound. In cat scratch disease the inoculation site can usually be found if systematically sought. In our series $75 \%$ of the patients had an identifiable lesion at the scratch site.

This is the first study of serologically proved cat scratch disease in Greece and to our knowledge one of the few reporting serial antibody determinations in children. ${ }^{12}{ }^{13}$ In recent years there has been a substantial increase in the number of pets, especially kittens, in Greek households. We therefore expect the incidence of cat scratch disease to increase. We believe that the indirect fluorescent antibody test for $B$ henselae will be a useful tool in the rapid diagnosis of the disease.
We thank Dr James G Olson PhD, Chief, Viral and Rickettsial Zoonoses Branch, Division of Viral and Rickettsial Diseases, National Center for Infectious Diseases, Center for Disease Control and Prevention, Atlanta, Georgia, USA, for performing the indirect fluorescent antibody test in our patients.

1 Zangwill KM, Douglas HH, Perkins BA, et al. Cat scratch disease in Connecticut: epidemiology, risk factors and evaluation of a new diagnostic test. $N$ Engl $f \mathrm{Med}$ 1993;329:8-13.

2 Kohler JE, Glaser CA, Tappero JW. Rochalimaea henselae infection: a new zoonosis with the domestic cat as reservoir. 7AMA 1994;271:531-5.

3 Carithers HA. Diagnosis of cat scratch disease. Pediatrics 1985;76:325.

4 Carithers HA. Cat-scratch disease. An overview based on a study of 1,200 patients. Am f Dis Child 1985;139:1124-33.

5 Carithers HA, Margileth AM. Cat-scratch disease. Acute encephalopathy and other neurologic manifestations. Am 7 Dis Child 1991;145:98-101.

6 Regnery RL, Olson JG, Perkins BA, et al. Serological response to 'Rochalimaea henselae' antigen in suspected cat-scratch disease. Lancet 1992;329:1443-5.

7 Margileth AM. Antibiotic therapy for cat-scratch disease: clinical study of therapeutic outcome in 268 patients and a review of the literature. Pediatr Infect Dis ₹ 1992;11:474-8.

8 Gerber MA, Rapacz P, Kalter SS, et al. Cell-mediated immunity in cat-scratch disease. $\mathcal{F}$ Allergy Clin Immunol 1986;78:887-90.

9 Margileth AM, Wear DJ, English CK. Systematic cat scratch disease: report of 23 patients with prolonged, recurrent, severe bacterial infection. F Infect Dis 1987;155:390-402.

10 Jackson LA, Spach DH, Kippen DA, et al. Seroprevalence to Bartonella quintana among patients at a community clinic in downtown Seattle. F Infect Dis 1996;173:1023-6.

11 Anderson B, Sims K, Regnery R, et al. Detection of Rochalimaea henselae DNA in specimens from cat scratch disease patients by PCR. F Clin Microbiol 1994;32:942-8.

12 Spaulding WB, Hennesy JN. Cat scratch disease: a study of eighty-three cases. Am f Med 1960;8:504-9.

13 Dalton MJ, Robinson LE, Cooper J, et al. Use of bartonella antigens for serologic diagnosis of cat-scratch disease at a national referral center. Arch Intern Med 1995;155:1670-6. 